\title{
Determination Transition Resistance of Cathode-Polarized Main Pipeline on Magnetometery Data
}

\author{
Vladimir N. Krizsky \\ Department of Informatics and Computer Engineering, \\ Sankt-Petersburg Mining University, Sankt-Petersburg, Russia. \\ Corresponding author: krizsky@ rambler.ru \\ Pavel N. Alexandrov \\ Geoelectromagnetic Research Centre, \\ Schmidt Institute of Physics of the Earth, RAS, Moscow, Russia. \\ E-mail: alexandr@igemi.troitsk.ru \\ Alexey A. Kovalskii \\ LLC, Cyber Scan Technology, \\ Sterlitamak, Russia. \\ E-mail: aakov68@mail.ru \\ Sergey V. Victorov \\ Department of Mathematical Modeling, \\ Bashkir State University, Sterlitamak Branch, Sterlitamak, Russia. \\ E-mail: viktorov@rambler.ru
}

(Received on May 2, 2021; Accepted on November 25, 2021)

\begin{abstract}
The article deals with the inverse problem of determining the transient resistance of the main pipeline insulating coating. For this, UAV measurements of the magnetic induction vector modulus of the magnetic field excited by the system of electrochemical cathodic protection of pipelines are used. The solution method is based on Tikhonov's method for finding the extremal of the regularizing functional. The developed algorithm is implemented in software. The results of computational experiments are presented.
\end{abstract}

Keywords- Pipeline cathodic protection, UAV-magnetometry, Inverse problem, Transition resistance measurement.

\section{Introduction}

In terms of cargo transportation pipeline transport takes a leading position in the world. The main pipelines run is large and lengthens annually. To protect the main pipeline from corrosion, active and passive methods are combined in practice such as systems of electrochemical cathodic protection of pipelines, as a rule, with polymer outer insulating coating. Insulating coating suffers mechanical effect in the process of the pipeline functioning due to in-line pressure changes, ground shifting deformations etc., it gets older, it is negatively affected by humidity and ground acidity, microorganisms. As a result, there is corrosion of the pipe metal leading to the decrease in resisting power and pipeline operation term (see Cicek, 2013; Goldobina and Orlov, 2016; Lazzari and Pedeferri, 2006; Lazzari, 2011; Peabody, 2001a; Peabody, 2001b). The regularly held pipeline condition monitoring is a basis of safe and efficient run exploitation. Measurements of an electric field in the process of monitoring, carried out, as a rule, with the method of an outer electrode, are made on the ground surface over the pipeline (see ISO, 2003). The development of wearable 
magnetometric measurement systems (see Krapivinsky et al., 2016a; Krapivinsky et al., 2016b; Krapivinsky et al., 2019; Liao et al., 2011; Lyubchik, 2010; Lyubchik, 2012; Maximov et al., 2017; Saxon et al., 2012) makes it possible to raise the measurement efficiency (increase in the velocity of measurement data, cut on monitoring financial costs) in the air over the run. The next step in the development of efficiency monitoring of the pipeline runs is elaboration and application of intellectual robotized magnetometric systems on the basis of flying machines. The latter allow to increase a frequency of run monitoring and, consequently, improve the level of their safe exploitation by means of earlier prediction of problem zones - zones with a stress-stain state or pipelines segments with the critical state of an insulation coating (see Hausamann et al., 2003; Kamaeva et al., 2019).

The system of a cathode electrochemical protection of underground main pipelines is a source of constant artificially excited electric and magnetic fields. Injected by cathodic protection stations (CPS), when passing anode beds an electrical field with pipeline ground, its insulating coating, running down along the pipe metal towards the drainage points carries information on physical and geometrical properties of the system "anode/ground/pipe". An electric field excites a constant magnetic field which can be measured over a pipeline run. The criterion of the state is described in the terms of transition resistance value at the boundary of ground/pipe" along the run.

The working models of computing the parameters of cathodic protection of systems functioning are normally based on the formulae taking into account a single average for all the pipe leg value of an insulating coating exponentially decreasing during an operation term. Modern computer technologies with an artificial intellect (see Lapiga and Shchipachyov, 2019; Lapiga et al., 2021) make it possible to create digital twins of the operating pipeline runs (see Iureva et al., 2020; Riemer, 2000) including mathematical models of thermal and gas-hydrodynamic processes of the products transfer (see Fetisov et al., 2018a; Fetisov et al., 2018b; Seleznyov et al., 2007), strength models of pipes stress-strain state (see Iynbinder and Kamershtein, 1982), thawing mechanics and ground strain (see Borodavkin, 2003), scattering in electromagnetic fields of the cathodic protection system (see Bolotnov et al., 2008; Krizsky et al., 2019; Krizsky et al., 2020; Liu et al., 2014; Min et al., 2016; Mujezinovich et al., 2016) and so on. Computer modeling allows to specify processes, to make an account of a pipe segment beginning with some parts homogeneous in residual metal magnetization (between the welding joints) and less (about $1 \mathrm{~m}$ ). Controlling the monitored time dynamics of physical parameters of the segments, it is possible to make relevant efficient steps to carry out local repairing works or changes of operation modes, for instance, change of power of the station injected cathodic protection of current.

The paper presents a mathematical model to define transition resistance of pipeline insulation based on magnetometry in the air over the pipeline run. Mathematical model can be described as an inverse problem of a mathematical physics where the required function is a coefficient function of Newton's boundary condition at the "ground/pipe". In parallel with the mathematical models of direct problems computing electrical and magnetic fields of cathodic protection systems in isotropic homogeneous (see Bolotnov et al., 2008; Liu et al., 2014; Min et al., 2016; Mujezinovich et al., 2016), isotropic horizontally layered (see Krizsky et al., 2019) and anisotropic (see Krizsky et al., 2020) media a model of an inverse problem can be put into the basis of an analytical nucleus of computer appliance monitoring of the main pipeline runs. Focusing on the aspects of an inverse problem solution, let us start with an elementary case of a background medium - case of homogeneous isotropic background main pipeline ground of constant electric conductivity. 


\section{Mathematical Model of an Inverse Problem and Algorithm of its Solution} Forward Problem (FP)

Suppose there is given space divided by plane boundary $\gamma_{0}\{z=0\}$ into two half spaces $\Omega_{0}$ and $\Omega_{1}$, where $\Omega_{0}$ - air, $\Omega_{1}$ - ground (Figure 1). We introduce the Cartesian coordinate system $o X Y Z$ starting on the plane $\gamma_{0}$ and axis $o Z$ inward the earth. Let's $\sigma_{1}(\mathrm{Sm} / \mathrm{m})$ is ground electrical conductivity filling out space $\Omega_{1}$. Air electrical conductivity $\sigma_{0}(\mathrm{Sm} / \mathrm{m})$ is supposed to equal to zero.

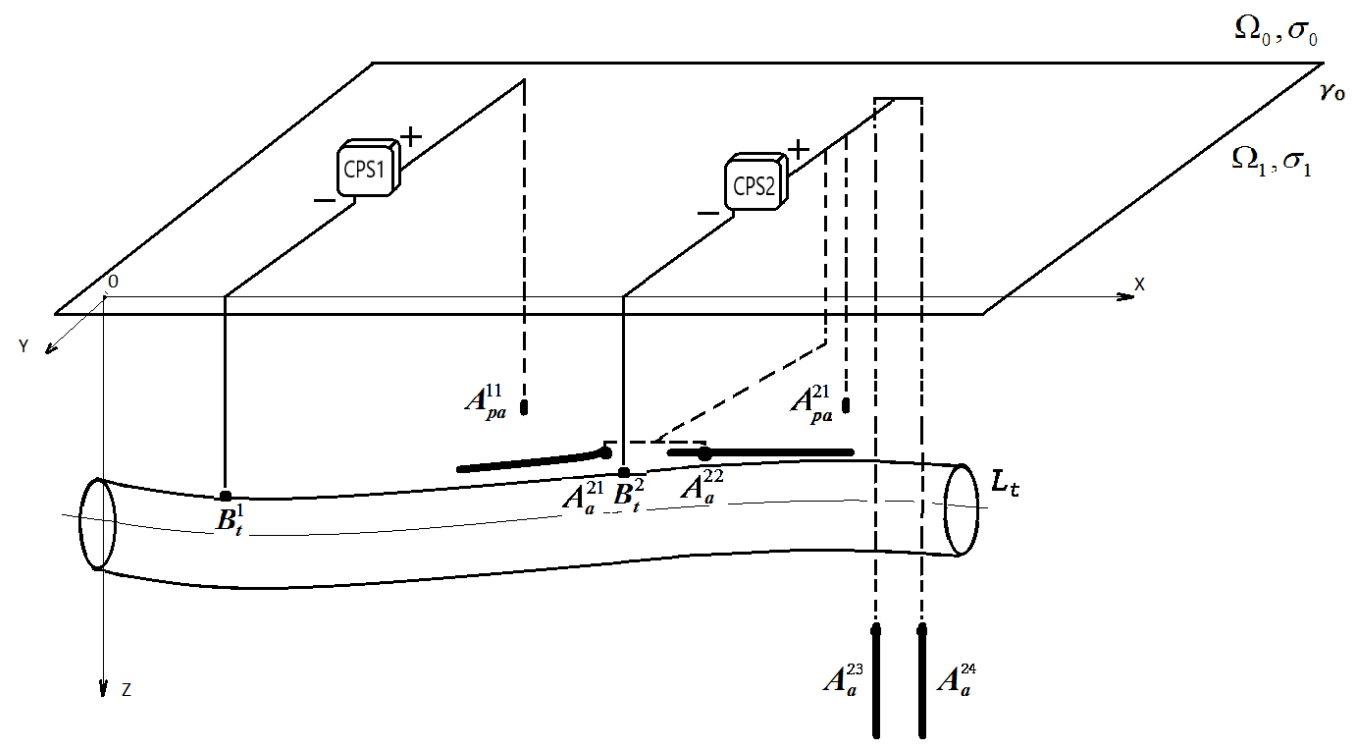

Figure 1. Scheme of cathodic protection in homogeneous isotropic half space.

Suppose in space $\Omega_{1}$ there is pipeline $V_{t}$ geometry of axis line of which is described with the parametric curve $V_{t}\left(x_{t}(s), y_{t}(s), z_{t}(s)\right), s \in\left[0, L_{t}\right]$, where $L_{t}$ is length of a pipe. Let's consider marginal parameter value $s$ equal to 0 and $L_{t}$ to correspond to the check marks through which electric power in the pipe metal does not flow along the pipe. Radius $R_{t}(\mathrm{~m})$, specific conductivity of pipe metal $\sigma_{t m}(\mathrm{Sm} / \mathrm{m})$ and square of pipe metal cross section $S_{t m}\left(\mathrm{~m}^{2}\right)$ are to be known. Given electrochemical pipe protection realized by $N_{C S}$ (items) cathodic protection stations (CPS), each of them ejects protective direct current into the ground across anodal beds - anode $V_{a}^{k n}\left(n=\overline{1, N_{a}^{k}}\right)$ and (or) point anode $A_{p a}^{k n}\left(x_{p a}^{k n}, y_{p a}^{k n}, z_{p a}^{k n}\right)\left(n=\overline{1, N_{p a}^{k}}\right)(k-$ CPS number). Axis lines of extended anode beds are presented in parameters $-V_{a}^{k n}\left(x_{a}^{k n}(s), y_{a}^{k n}(s), z_{a}^{k n}(s)\right), s \in\left[0, L_{a}^{k n}\right]$. Here $L_{a}^{k n}$ is length (m) of $n$-th of extended anode of $k$-th station of CP. Current lead of $I_{a}^{k n}$ (A) power to extended anodes is done in $A_{a}^{k n}\left(x_{a}^{k n}, y_{a}^{k n}, z_{a}^{k n}\right)$. Radii $R_{a}^{k n}(\mathrm{~m})$ in circular extended anodal beds, specific conductivity of their metal bars $(\mathrm{Sm} / \mathrm{m})$, square of metal cross section $S_{a m}^{k n}\left(\mathrm{~m}^{2}\right)$, transition resistance of anode filling $c_{a g}^{k n}(\mathrm{~s})\left(\mathrm{Ohm} \cdot \mathrm{m}^{2}\right)$ are known. Current of $I_{p a}^{k n}(\mathrm{~A})$ gets into the system through the point anodes found in $A_{p a}^{k n}\left(x_{p a}^{k n}, y_{p a}^{k n}, z_{p a}^{k n}\right)\left(n=\overline{1, N_{p a}^{k}}\right)$. Current drain of $I_{t}^{k}$ (A) with the pipeline interface towards $k$-th cathodic station is arranged in $B_{t}^{k}\left(x_{t}^{k}, y_{t}^{k}, z_{t}^{k}\right), k=\overline{1, N_{C S}}$. Current generated by $k$-th station $\sigma_{a m}^{k n}$ is known to be equal to $I_{0}^{k}$ Ampere. Let's specify the 
function of current potential in $P(x, y, z)$ of sub-space $\Omega_{1}$ in $U_{1}(P)(\mathrm{V})$, in the pipe metal $U_{t m}(P)$ $(\mathrm{V})$, in extended anodal bed $U_{a m}^{k n}(P)(\mathrm{V})$.

The mathematical model used to describe the distribution of the DC potential in the system can be represented as (see Krizsky et al., 2019; Krizsky et al., 2020):

$$
\begin{aligned}
& \operatorname{div}\left(\sigma_{1} \cdot \bar{\nabla} U_{1}(P)\right)=-\sum_{k=1}^{N_{C S}} \sum_{n=1}^{N_{p a}^{k}} I_{p a}^{k n} \cdot \delta\left(P-A_{p a}^{k n}\right), P \in \Omega_{1} \\
& \operatorname{div}\left(\sigma_{t m} \cdot \bar{\nabla} U_{t m}(P)\right)=0, P \in \Omega_{t} \\
& \operatorname{div}\left(\sigma_{a m}^{k n} \cdot \bar{\nabla} U_{a m}^{k n}(P)\right)=0, k=\overline{1, N_{C S}}, n=\overline{1, N_{a}^{k}}, P \in \Omega_{a} \\
& \left.\left(\sigma_{1} \cdot \bar{\nabla} U_{1}(P), \overrightarrow{\mathbf{n}}\right)\right|_{z=0}=0 ; \quad U_{1}(P) \rightarrow 0, P \rightarrow \infty \\
& \partial U_{t m}(P) /\left.\partial s\right|_{s=0 ; L_{t}}=0 \\
& U_{1}(P)-\left.c_{g t}(s)\left(\sigma_{1} \cdot \bar{\nabla} U_{1}(P), \overrightarrow{\mathbf{n}}\right)\right|_{S_{g t}}=U_{t}(P) \\
& U_{1}(P)+\left.c_{a g}^{k n}(s)\left(\sigma_{1} \cdot \bar{\nabla} U_{1}(P), \overrightarrow{\mathbf{n}}\right)\right|_{S_{a g}^{k n}}=U_{a}^{k n}(P), k=\overline{1, N_{C S}}, n=\overline{1, N_{a}^{k}} \\
& {\left.\left[\frac{\partial U_{t}^{k}}{\partial s}\right]\right|_{B_{t}^{k}}=\frac{I_{0}^{k}}{\sigma_{t m} S_{t m}}, k=\overline{1, N_{C S}} ;\left.\left[\frac{\partial U_{a}^{k n}}{\partial s}\right]\right|_{A_{a}^{k n}}=\frac{I_{a}^{k n}}{\sigma_{a m}^{k n} S_{a m}^{k n}}, k=\overline{1, N_{C S}}, n=\overline{1, N_{a}^{k}}}
\end{aligned}
$$

Here: (1) - equation of current distribution in the ground, (2) - equation of current in pipe metal, (3) - equation of current in metal of extended anodal beds, (4) - condition of current inflowing at the boundary "air/ground" and condition of solution regular intervals in infinity. Boundary conditions (5) show the current absence through frontal pipe ends. Condition (6) represents a condition of current flow at the lateral boundary $S_{g t}$ of "ground/pipe", where coefficient function $c_{g t}(s)$ is transition resistance of the pipe insulation. Boundary conditions (7) set the conditions of current flow at the boundaries $S_{a g}^{k n}$ "extended anode/ground" where coefficient function $c_{a g}^{k n}(s)$ is transition resistance of anodal filling. Conditions (8) include cathodic station connection to pipes and extended anodal beds. In boundary conditions (4), (6), (7) expression $\left(\sigma_{1} \bar{\nabla} U_{1}(P), \overrightarrow{\mathbf{n}}\right)$ is a scalar product of vectors or projection of a vector gradient of current potential multiplied by the coefficient of specific conductivity $\sigma_{1}$, by the external normal vector to the corresponding boundary.

To solve direct problem (1)-(8) a method of digitalization (pseudo-source method) can be applied, details of which are given in Bolotnov et al. (2008), Tkachenko (2007). Due to the method pipeline $V_{t}$ is divided into $M_{t}$ of different segments while each of extended anodal bed $V_{a}^{k n}\left(k=\overline{1, N_{C S}}\right.$, $n=\overline{1, N_{a}^{k}}$ ) is divided into $M_{a}^{k n}$ of equal segments. Each of these segments is considered to keep constant electric parameters (potentials $U_{a m}^{k n}, U_{t m}$ and current $I_{a m}^{k n}, I_{t m}$ flowing in the metal of extended anode and in the pipe metal; potentials $U_{a g}^{k n}, U_{t g}$ and $I_{a g}^{k n}, I_{t g}$ current flowing through the boundaries "extended anode/ground" and "ground/pipe") and equal to some average for each segment value. Each segment of the extended anodes is viewed as a pseudo-point current source while each pipe segment - as a point current drain. The values of current potential at any point of half space $\Omega_{1}$ can be presented in:

$U_{1}(P)=\sum_{k=1}^{N_{C S}} \sum_{n=1}^{N_{p a}^{k}} I_{p a}^{k n} G\left(P, A_{p a}^{k n}\right)+\sum_{k=1}^{N_{C S}} \sum_{n=1}^{N_{p a}^{k}} \sum_{i=1}^{M_{a}^{k n}} I_{a g i}^{k n} G\left(P, A_{a i}^{k n}\right)-\sum_{j=1}^{M_{t}} I_{t g j}^{k n} G\left(P, B_{t j}\right)$ 
Here function $G(P, Q)$ corresponds to Green function of host space (function defining the value of current potential in a homogeneous half space at $P\left(\mathbf{r}_{P}\right)=P\left(x_{P}, y_{P}, z_{P}\right)$, if pointed current source of a single intensity is found at $Q\left(\mathbf{r}_{Q}\right)=Q\left(x_{Q}, y_{Q}, z_{Q}\right)$ of half space). Function $G(P, Q)$ can be presented as:

$G(P, Q)=\frac{1}{4 \pi \sigma_{1}}\left[\frac{1}{\sqrt{\left(x_{P}-x_{Q}\right)^{2}+\left(y_{P}-y_{Q}\right)^{2}+\left(z_{P}-z_{Q}\right)^{2}}}+\frac{1}{\sqrt{\left(x_{P}-x_{Q}\right)^{2}+\left(y_{P}-y_{Q}\right)^{2}+\left(z_{P}+z_{Q}\right)^{2}}}\right]$

The current density at any point $P\left(\mathbf{r}_{P}\right)$ of the soil in the half-space with the pipeline is found from (9) by the formula:

$\mathbf{j}_{1}\left(\mathbf{r}_{\mathbf{P}}\right)=-\sigma_{1} \cdot \bar{\nabla} U_{1}\left(\mathbf{r}_{\mathbf{P}}\right), P \in \Omega_{1}$

where, the component of gradient vector $\bar{\nabla} U_{1}\left(\mathbf{r}_{\mathbf{P}}\right)$ determination leads to vector $\bar{\nabla} G(P, Q)$ determination.

Suppose host half space for a pipeline to be homogeneous, isotropic and constant by its magnetic properties. Hence, vector of magnetic induction $\mathbf{B}\left(\mathbf{r}_{\mathbf{0}}\right)$ at any space point defined by radius-vector $\mathbf{r}_{\mathbf{0}}$ (including in the air over the pipeline run) can be calculated with the formula of Biot-SavartLaplace according to the well-known distribution of vector field of current density $\mathbf{j}(\mathbf{r})$ :

$\mathbf{B}\left(\mathbf{r}_{\mathbf{0}}\right)=\frac{\mu \mu_{0}}{4 \pi} \int_{V} \frac{\left[\mathbf{j}(\mathbf{r}) d V, \mathbf{r}_{\mathbf{0}}-\mathbf{r}\right]}{\left|\mathbf{r}_{\mathbf{0}}-\mathbf{r}\right|^{3}}$

where, $[\because, \cdot]$ is a vector product, $\mu_{0}=4 \pi \cdot 10^{-7}$ is a magnetic constant, $\mu$ is a relative magnetic permeability (see Landau and Lifshits, 1988).

The schematic solution of a direct problem - the problem of calculation of vector field of magnetic induction over the pipeline run excited by the current of the system of cathodic electrochemical protection can be given in the following way:

$U\left(\mathbf{r}, c_{g t}(s)\right) \stackrel{(11)}{\longrightarrow} \mathbf{j}\left(\mathbf{r}, c_{g t}(s)\right) \stackrel{(12)}{\longrightarrow} \mathbf{B}\left(\mathbf{r}_{\mathbf{0}}, c_{g t}(s)\right)$

where the points with radius-vector $\mathbf{r}_{\mathbf{0}}$ are found at the measuring path of sensors of magnetometer $V_{U A V}$. In scheme (13) there is specially defined the dependence of calculated fields on the required function of transition resistance of insulated pipe coating, i.e. function $c_{g t}(s)$. In the method of pseudo sources function $c_{g t}(s)$ is piecewise constant. It is used to describe average for a discrete pipe segment transition resistance of its insulated coating. The arrows are marked by numbers of formulas.

\section{Inverse Problem (IP)}

Let the function of transition resistance of insulated coating of pipe $c_{g t}(s)$ is not known on boundary $S_{g t} \in \Omega_{1}$. Determine this function from measurements of the module of vector magnetic induction $\mathbf{B}^{U A V}$ on line $V_{U A V} \in \Omega_{0}$. To solve this problem let's apply a variation method of A.N. Tikhonov (see Tikhonov and Arsenin, 1986; Yagola et al., 2014), according to which the solution $c_{g t}(s)$ is achieved as an extremal (minimizing element) of a regularization functional:

$F^{\alpha}\left(c_{g t}(s)\right)=F_{1}\left(c_{g t}(s)\right)+\alpha F_{2}\left(c_{g t}(s)\right)$ 
for the forward problem FP (1)-(9), (11), (12). In the Tikhonov's functional (14):

$F_{1}\left(c_{g t}(s)\right)=\left\|\left|\mathbf{B}\left(\mathbf{r}_{\mathbf{0}}, c_{g t}(s)\right)\right|-\left|\mathbf{B}^{U A V}\left(\mathbf{r}_{\mathbf{0}}, c_{g t}(s)\right)\right|\right\|_{L_{2}\left(V_{U A V}\right)}^{2}-\quad$ residual functional; $\left|\mathbf{B}^{U A V}\left(\mathbf{r}_{0}, c_{g t}(s)\right)\right|$ - module of vector magnetic induction measured with a magnetometer; $\left|\mathbf{B}\left(\mathbf{r}_{\mathbf{0}}, c_{g t}(s)\right)\right|$ - module of vector magnetic induction - solution of the FP (1)-(9),(11),(12); $F_{2}\left(c_{g t}(s)\right)=\left\|c_{g t}^{0}(s)-c_{g t}(s)\right\|_{K\left(V_{t}(s)\right)}^{2}-$ regularization functional, $c_{g t}^{0}(s)-$ a priori given transition resistance of insulation along the pipe (obtained, for example, on the findings of a previous run monitoring relying on insulation ageing during the time between the checks); $c_{g t}(s)$ - required function of transition resistance of pipe's insulation coating; $\alpha$ - Tikhonov's regularization parameter; $V_{U A V}$ - sensors paths of magnetometric system in the air; $L_{2}$ - space of the square-integrable functions determined on line $V_{U A V} ; K\left(V_{t}(s)\right.$ ) - compact set of limited piecewise constant functions.

Algorithm 1. Optimization algorithm

1: Set the baseline insulation resistance values for all pipe segments by the constant function. Simulate "defective" segments by reducing the base values of the insulation resistance on them - get function $c_{g t \_d e f}(s)$.

2: Solve the forward problem FP (1)-(9),(11),(12) for insulation resistance distribution $c_{g t_{d} \text { def }}(s)$ on line $V_{U A V}$ - determine module of vector magnetic induction $\left|\mathbf{B}\left(\mathbf{r}_{\mathbf{0}}, c_{g t_{-} \text {def }}(s)\right)\right|$. Add into the module random noise of the given level $\delta_{n}(10,20 \%)$ with the proportional probabilistic distributional law - form the file of the "measured" magnetometric data $\left|\mathbf{B}^{U A V}\left(\mathbf{r}_{\mathbf{0}}, c_{g t}(s)\right)\right|$ for the residual functional of A.N. Tikhonov's regularizing functional (14).

3: "Forgot" the given data on the "defective" segments - consider the situation when all the pipe segments (including defective) had only basic properties. Take into account at the process of the stabilizing functional a priori given function $c_{g t}^{0}(s)$.

4: Solve the inverse problem IP - find an extremal solution minimizing the regularization functional (14) - get $c_{g t}^{*}(s)$ piecewise constant on the pipe segments function of transition resistance at the boundary "ground/pipe". Value of regularizing parameter $\alpha$ is taken as equal to 0,001 .

5: On the basis of the obtained function $c_{g t}^{*}(s)$ compute the measure of deviation of the obtained solution of the initial resistance function $c_{g t_{-} d e f}(s)$ - Euclid's (spherical) vector norm $\rho_{c}=\left\|c_{g t}^{*}(s)-c_{g t_{-} d e f}(s)\right\|$ with the form of $\rho_{c}=\sqrt{\sum_{i=1}^{M_{t}}\left(c_{g t, i}^{*}(s)-c_{g t_{-} d e f, i}(s)\right)^{2}}$ for a discrete function.

6: Compute the value of magnetic fields difference $\rho_{B}=$ $\sqrt{\sum_{i=1}^{M_{t}}\left(\left|\mathbf{B}_{i}\left(r_{0}, c_{g t}^{*}(s)\right)\right|-\left|\mathbf{B}_{i}\left(r_{0}, c_{g t_{-} d e f}\right)\right|\right)^{2}}$.

\section{Results of Simulation Experiments}

A well-known zero-order method by Hooke-Jeeves (configurations) (see Kelley, 1999) is applied as a method for minimizing of functional (14). The method shows a close similarity, compared with the other zero-order methods, to a small number of applications in direct problems solutions in search of a minimum of a strong ravine function for boundary geoexploration problem (see 
Krizsky et al., 2015). Such property of the method makes it possible to cut the time of a computerized system work to find a solution.

The Algorithm 1 was used for solution of the inverse problem IP using high-performance code written in $\mathrm{C}++$. In the simulation experiments above half space of the main pipelines is homogeneous isotropic with ground conductivity $\sigma_{1}=0,0163 \mathrm{Sm} / \mathrm{m}$. Table 1 shows parameters values of the simulation experiments. It is supposed that on the pipe pieces with the length of $h_{s g m}$ (m) its physical properties can be considered constant. In the experiment is studied a simplifying model where extended anodal beds are missing and current is injected into the system only from pointed anodal beds. In this case equations (3), limiting condition (8) and secondary equality (9) are excluded. As pipes" "defective" segments where transition resistance of insulation differs from the "basic" one there are specified both separate segments and systematic imitating local and extended drawbacks. Their numbers, $x$-coordinates of midplanes, resistance values in $0 \mathrm{Oh}^{*} \mathrm{~m}^{2}$ and $\%$ of the basic are presented in Table 1 .

Table 1. Parameters used in the experimental set-up.

\begin{tabular}{|c|c|c|c|c|c|c|c|c|c|c|c|c|c|c|c|c|}
\hline \multicolumn{4}{|c|}{ Parameters } & \multicolumn{3}{|c|}{$\begin{array}{c}\text { Parameters } \\
\text { Values }\end{array}$} & \multicolumn{6}{|c|}{ Parameters } & \multicolumn{4}{|c|}{$\begin{array}{l}\text { Parameters } \\
\text { Values }\end{array}$} \\
\hline \multicolumn{7}{|l|}{ Pipeline } & \multicolumn{10}{|c|}{ Cathodic protection nodes } \\
\hline \multicolumn{4}{|c|}{ Length of the protected piece, m., $L_{1}$} & \multicolumn{3}{|c|}{16260.0} & \multicolumn{6}{|c|}{ Number of service stations, $\mathrm{nmb} ., N_{c S}$} & \multicolumn{4}{|c|}{2} \\
\hline \multicolumn{4}{|l|}{ Outer diameter, m., $D_{t}$} & \multicolumn{3}{|c|}{0.53} & \multirow{3}{*}{$\overline{\tilde{n}}$} & \multicolumn{5}{|c|}{ Running current, A., $I_{0}^{1}$} & \multicolumn{4}{|c|}{1.2} \\
\hline \multicolumn{4}{|l|}{ Wall thickness, m., $h_{t m}$} & \multicolumn{3}{|c|}{0.008} & & \multicolumn{5}{|c|}{$\begin{array}{l}\text { Drainage point coordinates, } \mathrm{m} . \text {, } \\
B_{t}^{1}\left(x_{t}^{1}, y_{t}^{1}, z_{t}^{1}\right)\end{array}$} & \multicolumn{4}{|c|}{$(5001.2 ; 0.0 ; 1.7)$} \\
\hline \multicolumn{4}{|c|}{ Steel electric resistance, Ohm*m, $1 / \sigma_{t m}$} & \multicolumn{3}{|c|}{$2.45^{*} 10^{-7}$} & & \multicolumn{5}{|c|}{$\begin{array}{l}\text { Pointed anode bed coordinates, } \\
\text { m., } A_{p a}^{11}\left(x_{p a}^{11}, y_{p a}^{11}, z_{p a}^{11}\right)\end{array}$} & \multicolumn{4}{|c|}{$(5000.0 ; 240.0 ; 22.5)$} \\
\hline \multicolumn{4}{|c|}{ Occurrence depth (axially), m, $h_{t}$} & \multicolumn{3}{|c|}{1.435} & \multirow{3}{*}{$\tilde{n}^{2}$} & \multicolumn{5}{|c|}{ Running current, A., $I_{0}^{2}$} & \multicolumn{4}{|c|}{0.8} \\
\hline \multicolumn{4}{|c|}{$\begin{array}{l}\text { Transition resistance of insulation } \\
\text { (basic), } \mathrm{Ohm} * \mathrm{~m}^{2}, c_{g t}^{0}\end{array}$} & \multicolumn{3}{|c|}{14685.6} & & \multicolumn{5}{|c|}{$\begin{array}{l}\text { Drainage point coordinates, } \mathrm{m} . \text {, } \\
B_{t}^{2}\left(x_{t}^{2}, y_{t}^{2}, z_{t}^{2}\right)\end{array}$} & \multicolumn{4}{|c|}{$(12999.8 ; 0.0 ; 1.7)$} \\
\hline \multicolumn{4}{|c|}{ Host medium } & & & & & $\begin{array}{l}\text { Pointed } \\
\text { m., } A_{p a}^{21}\end{array}$ & $\begin{array}{l}\text { anoda } \\
\left(x_{p a}^{21}, y\right.\end{array}$ & $\begin{array}{l}\text { bed c } \\
21, z_{p a}^{21}\end{array}$ & ordin & & $(130$ & 00.0 & 45.0 & 2.5) \\
\hline Current conductivity, & $\sigma_{1}$, & $\mathrm{Sm} / \mathrm{m}$ & & 0.000 & $0,0.01$ & & Meas & uremen & para & neters & & & & & & \\
\hline Sampling parameter: & & & & & & & $\begin{array}{l}\text { Heigh } \\
\text { meast }\end{array}$ & $\begin{array}{l}\text { at of dis } \\
\text { uring sy }\end{array}$ & $\begin{array}{l}\text { lacem } \\
\text { tem, }\end{array}$ & tof s & & & $\begin{array}{c}\mathrm{h}_{\mathrm{ms}} \\
\text { koe }\end{array}$ & $\begin{array}{l}=h_{s \varepsilon} \\
f=\{\end{array}$ & $\begin{array}{l}n * k c \\
.5,2,\end{array}$ & \\
\hline $\begin{array}{l}\text { Number of segments, } \\
\text { (segment length, m., } h\end{array}$ & b., & & & 990 & $(16.42$ & & & Noise le & rel in $\mathrm{tl}$ & e data & $\%, \delta$ & & & & 20 & \\
\hline & & & & & & efe & e»se & gments & & & & & & & & \\
\hline Number of segments & 401 & 402 & 403 & 404 & 405 & 406 & 407 & 408 & 409 & 410 & 411 & 412 & 421 & 422 & 423 & 430 \\
\hline $\mathrm{X}$-coordinate, $\mathrm{m}$. & $\frac{\sigma}{\hat{\sigma}}$ & 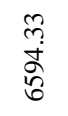 & $\frac{0}{\stackrel{0}{0}}$ & 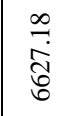 & $\begin{array}{l}\vec{\sigma} \\
\tilde{\theta} \\
\dot{\theta}\end{array}$ & $\begin{array}{l}0 \\
0 \\
0 \\
0 \\
0\end{array}$ & 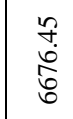 & $\begin{array}{l}\infty \\
\infty \\
i \\
\delta \\
\delta\end{array}$ & $\begin{array}{l}\stackrel{0}{2} \\
\stackrel{\rho}{0}\end{array}$ & 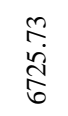 & $\frac{n}{\frac{n}{\pi}}$ & $\begin{array}{l}\hat{n} \\
\infty \\
n \\
6\end{array}$ & $\begin{array}{l}\text { లి } \\
\text { ठ̊ } \\
\text { వి }\end{array}$ & 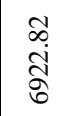 & 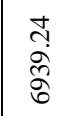 & $\begin{array}{l}\bar{N} \\
\dot{t} \\
\stackrel{r}{r}\end{array}$ \\
\hline $\begin{array}{c}\text { Transition resistance, } \\
\text { Ohm* }{ }^{2}, c_{g t \_d e f} \\
(\% \text { of basic })\end{array}$ & 440 & & & & & .56 & & & & & & & & & $\begin{array}{l}8.56 \\
0)\end{array}$ & \\
\hline
\end{tabular}

Figure 2 shows function graph $c_{g t_{-} d e f}(x)\left(\mathrm{Ohm}^{*} \mathrm{~m}^{2}\right)$ - given, with account of resistance of "defective" segments, transition resistance along the pipeline. As a part of the study there is taken a segment of the pipeline between the drainage points of two cathodic stations excluding stretches of 200 meter long bordering with the drainage points. The segments 200 meters long were taken for analysis supposing that on more than 200 meters distance the impact of magnetic field is insignificant. Are not analyzed segments from 0 to the first cathodic station, and after the second 
cathodic station to the pipe end. The choice of the segment was conditioned by: 1) inclination to take into account currents from the both cathodic stations in the place of their combined impact on the pipeline; 2) intention not to take into account run segments outside the drainage points when computing magnetic fields (during integrating process).

The algorithm for solving the forward problem FP allows one to calculate electromagnetic fields characteristics of the of cathodic protection systems that are important for practice. These characteristics include the protective potential at the "ground/pipe" interface, the potential of the electric field at the "soil/air" surface, the density of the electric current flowing in the pipe metal, and the modulus of the magnetic induction vector in the air above the pipeline. Figure 3 shows a graph of the magnetic induction vector modulus $\mathbf{B}\left(r_{0}, c_{g t}(s)\right)$ at a height of 1 meter in air above the axis of the pipeline (on a straight line $V_{U A V}$ ).

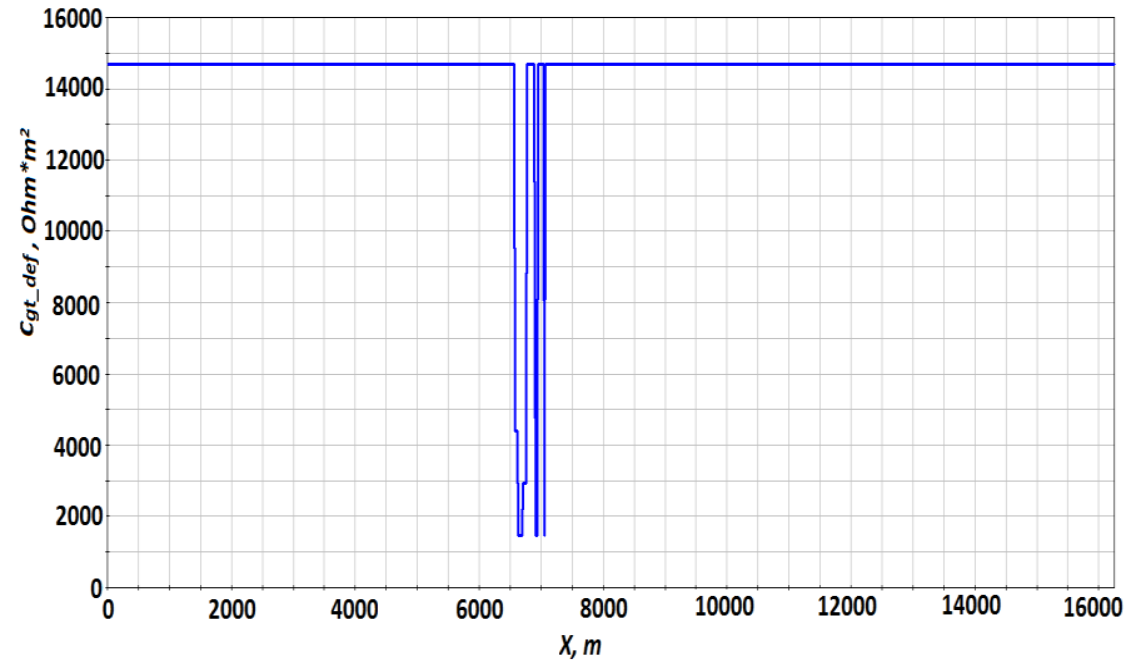

Figure 2. Given transition resistance of insulation $\left(\mathrm{Ohm}^{*} \mathrm{~m}^{2}\right)$ at the boundary "ground/pipe".

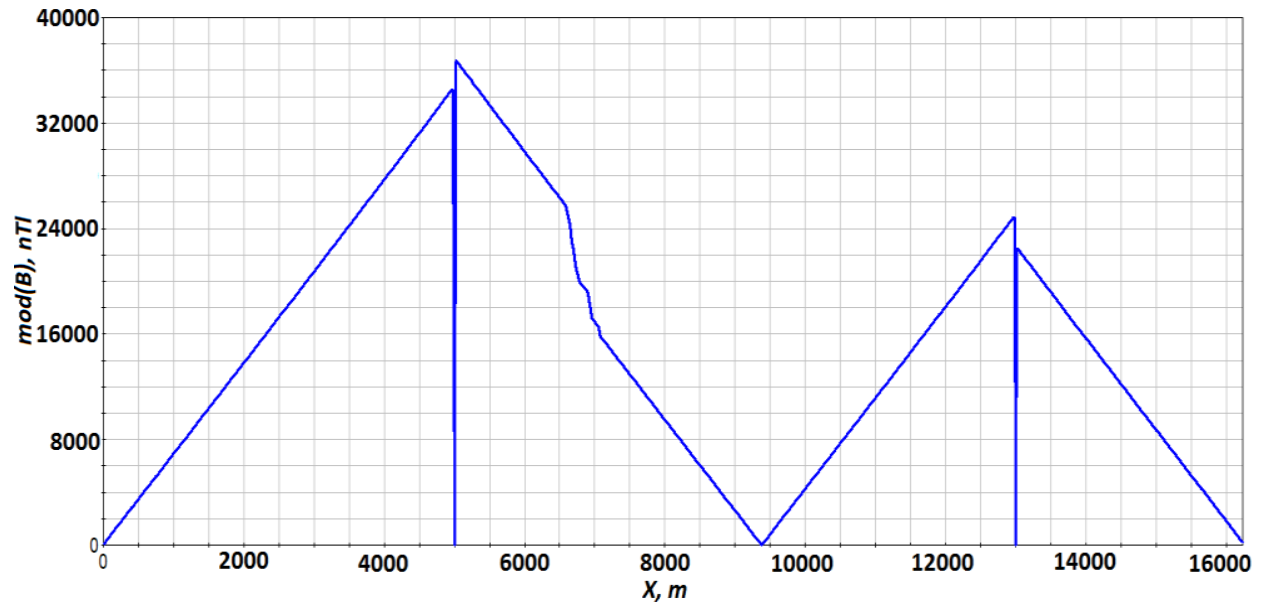

Figure 3. Module of magnetic induction vector $(\mathrm{T})$ at height of $1 \mathrm{~m}$. in the air over the pipeline axis. 
Figure 4 shows the results of computational experiments performed in accordance with the above algorithm for solving the inverse problem IP. Here are the values of the found transient resistances at the «soil/pipe» interface depending on the variation in the level of uniform noise added to the initial data $\left(\delta_{n}=10\right.$ and $20 \%$ ) and the values of the multiplicative coefficient koef that determines the flight altitude of the sensors of the magnetometric system. Comparison of the $\rho_{c}$ values shows that the best heights of magnetometric measurements for determining the transient insulation resistance are heights from 2 to 4 lengths of pipe sampling sections.

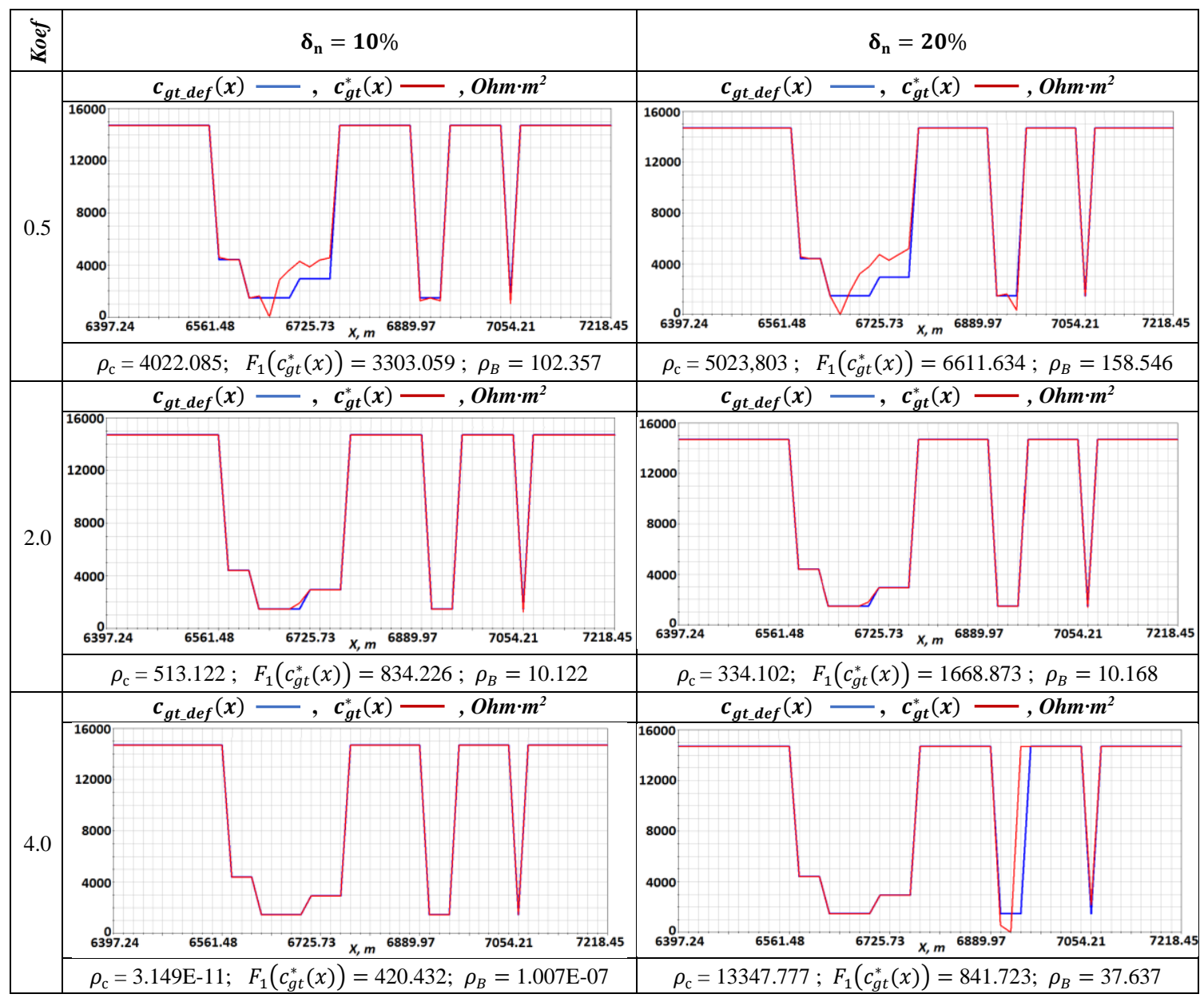

Figure 4. Comparison of the given $\left(\boldsymbol{c}_{\boldsymbol{g} t_{-} \boldsymbol{d} \boldsymbol{e f}}(\boldsymbol{x})\right)$ and obtained $\left(\boldsymbol{c}_{\boldsymbol{g} t}^{*}(\boldsymbol{x})\right)$, as a solution of an inverse problem IP, functions of transition resistance at the boundary of "ground/pipe".

\section{Conclusions}

The article concerns the mathematical model of the mathematical geophysics problem to determine transition resistance at the boundary "ground/pipe" of the main pipeline on the basis of magnetometry data. Then inverse problem solution is found as an extremal of a regularizing functional by A.N. Tikhonov in the set of piecewise constant limited functions. There are given the results of the simulating experiments. The influence of the noise level in the given data and the 
height of movement of the sensors of the magnetometric system in air on the simulation results is shown.

The above mathematical model of the problem is simplified - it does not take into account the residual magnetic stress of the pipeline rings (between welded joints). Residual magnetization for each of the fragments is formed during the production of hot-rolled pipes. The model also does not take into account the influence of the magnetic field of the welded joints themselves, areas of the stress-strain state and other parameters. The influence of these and other unaccounted for parameters requires additional research and computer experiments. However, the above experiments show that, on the basis of the presented mathematical models, it is possible to determine the function of the transient resistance at the "ground/pipe" interface, which reflects the state of the pipeline insulation coating. To determine it more qualitatively, it may be necessary to fine-tune the parameters used in computational procedures (for example, the regularization parameter). Reducing the length of the pipe segment $h_{s g m}$ to a length of 1 meter typical for practical use, leads to an increase in the dimension of the inverse problem. This entails a significant increase in the simulation time and requires the use of multiprocessor systems and parallel programming technologies to speed up the computation or/and a neural network approximator for quickly solving direct problems used in the Tikhonov method.

\section{Conflict of Interest}

The authors confirm that there is no conflict of interest to declare for this publication.

\section{Acknowledgments}

The study was carried out at the expense of a subsidy for the fulfillment of the state task in the field of scientific activity No. FSRW-2020-0014. The authors would like to thank the editor and anonymous reviewers for their comments that help improve the quality of this work.

\section{References}

Bolotnov, A.M., Glazov, N.N., Glazov, N.P., Shamshetdinov, K.L., \& Kiselev, V.D. (2008). Mathematical model and algorithm for computing the electric field of pipeline cathodic protection with extended anodes. Protection of Metals, 44(4), 408-411. DOI: 10.1134/S0033173208040188.

Borodavkin, P.P. (2003). Ground mechanics. Nedra, Moscow.

Cicek, V. (2013). Cathodic protection: industrial solutions for protection against corrosion. John Wiley \& Sons, New York.

Fetisov, V.G., Nikolaev, A.K., \& Lykov, Y.V. (2018a). Aggregativ simulation method for implementing mathematical models for gas transmission systems. IOP Conference Series: Materials Science and Engineering, 327(2), C. 022033. DOI: 10.1088/1757-899X/327/2/022033

Fetisov, V.G., Nikolaev, A.K., Lykov, Y.V., \& Duchnevich, L.N. (2018b). Mathematical modeling of nonstationary gas flow in gas pipeline. IOP Conference Series: Materials Science and Engineering, 327(2), C. 022034. DOI: 10.1088/1757-899X/327/2/022034.

Goldobina, L.A., \& Orlov, P.S. (2016). Analysis of the corrosion destruction causes in underground pipelines and new solutions for increasing corrosion steel's resistance. Journal of Mining Institute. 219, 459-464. DOI: 10.18454/PMI.2016.3.459. 
Hausamann, D., Zirnig, W., \& Schreier, G. (2003). Monitoring of gas transmission pipelines - a customer driven civil UAV application. In: Proceedings of the ONERA-DLR Symposium ODAS S3-6-1-S3-6-15. https://elib.dlr.de/19883/.

ISO 15589-1: 2003 (E). (2003). Petroleum and natural gas industries - cathodic protection for pipeline transportation systems. Part 1: On-land Pipelines, 1-40.

Iureva, R.A., Kremlev, A.S., Subbotin, V., Kolesnikova, D.V., \& Andreev, Y.S. (2020). Digital twin technology for pipeline inspection. In: Czarnowski, I., Howlett, R., Jain, L. (eds) Intelligent Decision Technologies. IDT 2020. Smart Innovation, Systems and Technologies. Springer, Singapore, pp. 329339. DOI: 10.1007/978-981-15-5925-9_28.

Iynbinder, A.B., \& Kamershtein, A.G. (1982). Main pipelines computing on safety and stability. Nedra, Moscow.

Kamaeva, S.S., Kolesnikov, I.S., Eremin, N.A., \& Khusnutdinov, L.A. (2019). Remote inspection by the magnetic tomography method (MTM) to prevent the risks imposed by exploitation of arctic offshore pipelines. IOP Conference Series: Materials Science and Engineering, 700, 012051. DOI: 10.1088/1757-899X/700/1/012051.

Kelley, C.T. (1999). Iterative methods for optimization. SIAM, Philadelphia.

Krapivsky, E.I., \& Venkova, Yu. A. (2016a). Method of monitoring technical condition of underground pipelines on the basis of residual magnetic field. Patent RU 2584729 C1, 20.05.2016.

Krapivsky, E.I., \& Kapachinskih, Z.Y. (2019). Deep water pipelines. Business Journal Neftegaz.RU, 12(96), 102-104.

Krapivsky, E.I., Venkova, Yu. A., \& Demchenko, N.P. (2016b). Study of the stress state influence on induced pipelines magnetic field (Russian). Neftyanoe khozyaystvo-Oil Industry, 2016(03), 120-122.

Krizsky, V.N., Alexandrov, P.N., Kovalsky, A.A., \& Viktorov, S.V. (2019). Modelling of electromagnetic fields of cathodic protection systems of pipelines in horizontally layered media. Nauka i Tekhnologii Truboprovodnogo Transposta Nefti i Nefteproductov, 9(5), 558-567. DOI: 10.28999/2541-9595-20199-5-558-567.

Krizsky, V.N., Alexandrov, P.N., Kovalsky, A.A., \& Viktorov, S.V. (2020). Mathematical modelling of electric fields of cathodic protection of main pipelines in anisotropic Media. Nauka $i$ Tekhnologii Truboprovodnogo Transposta nefti i Nefteproductov, 10(1), 52-63. DOI: 10.28999/2541-9595-2020-101-52-63.

Krizsky, V.N., Viktorov, S.V., \& Belyaeva, M.B. (2015). Mathematical modelling of geoelectric fields in piecewise homogeneous quasi-three-dimension media. Sterlitamak, Sterlitamakskii filial BashGU.

Landau, L.D., \& Lifshits, E.M. (1988). Field theory. Nauka, Moscow.

Lapiga, I., Shchipachev, A., \& Osadchiy, D. (2021). Using of artificial neural networks to assess the residual resource of trunk pipelines. E3S Web of Conferences, Corrosion in the Oil \& Gas Industry 2020, 225, 02006. DOI: $10.1051 / \mathrm{e} 3$ sconf/202122502006.

Lapiga, I.R., \& Shchipachov, A.M. (2019). Artificial neural nets to estimate residual resource of gas and oil pipelines. Delovoy Zhurnal Neftegaz.RU, 12 (96), 46-52.

Lazzari, L. (2011). Corrosion risk assessment of pipelines based on cathodic protection survey. In: Bolzon G., Boukharouba, T., Gabetta, G., Elboujdaini, M., Mellas, M. (eds) Integrity of Pipelines Transporting Hydrocarbons. NATO Science for Peace and Security. C: Environmental Security. Springer, Dordrecht, pp. 285-309. DOI: 10.1007/978-94-007-0588-3_18.

Lazzari, L., \& Pedeferri, P. (2006). Cathodic protection. Polipress, Milano. 
Liao, K., Yao, Q., \& Zhang, C. (2011). Principle and technical characteristics of non-contact magnetic tomography method inspection for oil and gas pipeline. In International Conference on Pipelines and Trenchless Technology 2011: Sustainable Solutions for Water, Sewer, Gas, and Oil Pipelines (pp. 10391048) Beijing, China. DOI: 10.1061/41202(423)111.

Liu, C., Shankar, A., Orazem, M.E., \& Riemer, D.P. (2014). Numerical simulations for cathodic protection of pipelines. Underground Pipeline Corrosion, 85-26. Woodhead Publishing. https://doi.org/10.1533/9780857099266.1.85.

Lyubchik, A.N. (2010). Modern magnetic methods of control and prospect of technical condition of engineering constructions. Notes of Mining Institute, 186, 124-127.

Lyubchik, A.N. (2012). Method of distant magnetometric control of technical condition of main pipelines. Notes of Mining Institute, 195, 268-271.

Maximov, G.L., Nosov, F.V., Fogel, A.D., Semyonov, V.V., \& Yeliseev, A.A. (2017). Complex testing of pipeline technical condition. Corrosion: Territories «Neftegas», 37(2), 16-22.

Min, Du., Huanhuan, W., \& Shouzhi, H. (2016). Optimization of cathodic protection for structure in marine tidal zone. Proceedings of the EuroCorr. http://eurocorr.efcweb.org/2016/abstracts/JS\%202/ 61122.pdf.m.

Mujezinovich, A., Martinez, S., \& Muharemovich, A. (2016). Mathematical model for cathodic protection of the underground pipelines. Conference Paper. 25th Expert Meeting "Komunalna Energetika/Power Engineering” (pp.1-16). Maribor, Slovenia. https://www.researchgate.net/publication/304717123.

Peabody, A.W. (2001a). Control of pipeline corrosion. NACE, Houston.

Peabody, A.W. (2001b). Control of pipeline corrosion, anti-corrosion methods and materials. NACE 2001, 48(6). DOI: 10.1108/acmm.2001.12848fae.001.

Riemer, D.P. (2000). Modeling cathodic protection for pipeline networks. PhD Thesis, University of Florida, USA, Florida.

Sakson, V.M., Sergeev, A.B., \& Prokazin, A.B. (2012). Diagnostic of steel pipelines by method of contactfree magnetometry. Mir Izmereniy, 6, 17-21.

Seleznyev, V.E., Aleshin, V.V., \& Pryalov, S.N. (2007). Mathematical modelling in pipelines and canal systems: methods, models and algorithms. MAKS Press, Moscow.

Tikhonov, A.N., \& Arsenin, V.Ya. (1986). Methods of solutions of incorrect problems. Nauka, Moscow.

Tkachenko, V.N. (2007). Computing electrochemical protection of pipelines from corrosion by discretization method. Electrichestvo, 12, 41-47.

Yagola, A.G., Yanfei, V., Stepanova, I.E., \& Titarenko, V.N. (2014). Inverse problems and methods of their solutions. Application to geophysics. Binom, Laboratoriya Znaniy, Moscow. 